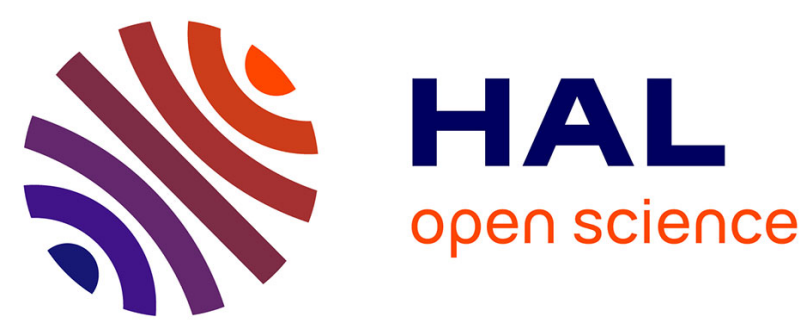

\title{
The facile dearomatization of nitroaromatic compounds using lithium enolates of unsaturated ketones in conjugate additions and $(4+2)$ formal cycloadditions
}

Karine Pasturaud, Batoul Rkein, Morgane Sanselme, Muriel Sebban, Sami Lakhdar, Muriel Durandetti, Julien Legros, Isabelle Chataigner

\section{To cite this version:}

Karine Pasturaud, Batoul Rkein, Morgane Sanselme, Muriel Sebban, Sami Lakhdar, et al.. The facile dearomatization of nitroaromatic compounds using lithium enolates of unsaturated ketones in conjugate additions and $(4+2)$ formal cycloadditions. Chemical Communications, 2019, 55 (52), pp.7494-7497. 10.1039/C9CC02924A . hal-03003225

\section{HAL Id: hal-03003225 https://hal.science/hal-03003225}

Submitted on 13 Nov 2020

HAL is a multi-disciplinary open access archive for the deposit and dissemination of scientific research documents, whether they are published or not. The documents may come from teaching and research institutions in France or abroad, or from public or private research centers.
L'archive ouverte pluridisciplinaire HAL, est destinée au dépôt et à la diffusion de documents scientifiques de niveau recherche, publiés ou non, émanant des établissements d'enseignement et de recherche français ou étrangers, des laboratoires publics ou privés. 
Received 00th January 20xx, Accepted 00th January 20xx DOI: $10.1039 / x 0 x \times 00000 x$

\section{Facile dearomatization of nitroaromatic compounds using lithium enolates of unsaturated ketones in conjugate additions and (4+2) formal cycloadditions}

\author{
Karine Pasturaud, ${ }^{\text {a }}$ Batoul Rkein, ${ }^{a}$ Morgane Sanselme, ${ }^{b}$ Muriel Sebban, ${ }^{a}$ Sami Lakhdar, ${ }^{c}$ Muriel \\ Durandetti, ${ }^{a}$ Julien Legros ${ }^{\mathrm{a}}$ and Isabelle Chataigner ${ }^{\mathrm{a}, \mathrm{d}}$ *
}

under drastic reaction conditions, including extended heating at high temperatures. ${ }^{4,5}$ Such harsh procedures lead to the rearomatization of the cycloadducts most of the time and thus loss of functional groups. Electrophilic activation of the dienophilic partner by acid catalysis (Lewis or Brønsted) usually allows to decrease the reaction temperature by lowering its LUMO energy. ${ }^{6}$ However, the acid sensitivity of the functionalized (silyl)oxydienes, such as Danishefsky diene for instance, prevents their use in many cases. ${ }^{7}$ High pressure activation has been shown to overcome this difficulty, allowing to perform the reactions in a range of temperatures compatible with most substrates/cycloadducts. ${ }^{4,5,8}$ But hyperbaric equipment being seldom available in organic laboratories, a more general alternative method is highly desirable. In this context, the less intuitive activation of the dienic partner, by raising its HOMO energy, appears as an attractive option. This has been considered through (poly)enamine catalysis, an elegant but somewhat limited strategy, notably for aromatic substrates..$^{\text {e-f, }, 9}$

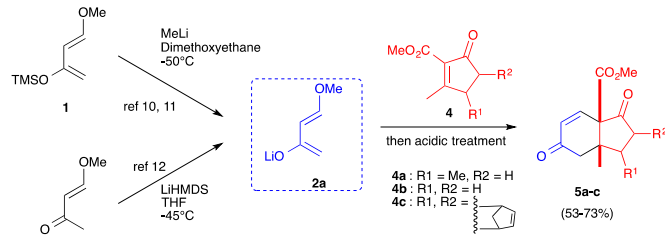

Scheme 1. Reaction between activated lithium enolate $\mathbf{2 a}$ and tetrasubstituted Scheme 1. Reaction between activated lithium enolate 2 a and
cumbersome dienophiles to afford formal $(4+2)$ cycloadducts.

In 1988, Baker et al. showed that a nucleophilic activation of Danishefsky diene 1 could overcome the lack of reactivity of inert tetrasubstituted dienophilic substrates, by transforming 1 into lithium enolate $\mathbf{2} \mathbf{a}$ in the presence of methyllithium in dimethoxyethane (DME) at $-50^{\circ} \mathrm{C}$ (Scheme 1). ${ }^{10}$ Reaction with the dienophile $4 \mathrm{a}$ occurred at $-90^{\circ} \mathrm{C}$ in THF to afford the Michael adduct, which was further cyclized under acidic conditions to provide the corresponding formal cycloadduct. Danishefsky et al. reported a related transformation, involving $\mathbf{4 b}$, in the context of the total synthesis of ( \pm )aplikurodinone. ${ }^{11}$ Recently, Snyder et al. performed a similar nucleophilic activation to access Hajos-Parrish ketone isomers 
from sterically hindered tetrasubstituted dienophiles $4 \mathrm{c}$ in a three-steps addition/cyclization/retro-Diels-Alder sequence. ${ }^{12}$ This successful nucleophilic activation of conjugated lithium enolate $\mathbf{2 a}$ led to the formal cumbersome cycloadduct $\mathbf{5}$, unreachable from 1 under classical conditions. We therefore wondered if this oxydienic nucleophilic activation path could be adapted to more challenging aromatic partners as dienophiles. This low-temperature procedure would give access to formal $(4+2)$ cycloadducts, and would be compatible with many sensitive substrates/products, thus extending the scope of dearomatizations and paving the way to novel polycyclic functionalized tridimensional scaffolds useful in the context of natural products or diversity oriented syntheses.

Inspired from Snyder's work, we first tried to generate the lithium enolate $\mathbf{2} \mathbf{a}$ from butenone $\mathbf{3 a}$ directly, avoiding the use of the more expensive silyloxydiene. 3a was slowly added to a preformed LDA solution, at $-78^{\circ} \mathrm{C}$, in THF, in order to prevent the usual condensation of the conjugated enolate anion on the butenone precursor, behaving as a Michael acceptor. Reaction of this preformed lithium enolate on the model tetrasubstituted ketone $\mathbf{4 b}$, gratifyingly led to results similar to those reported by Danishefsky from methoxytrimethylsilyloxybutadiene. ${ }^{13}$ This led us to use the methoxybutenone $3 a$ as enolate precursor in standard conditions $\left(\mathrm{THF}\right.$, at $-78^{\circ} \mathrm{C}$ ) for the dearomatization study (see ESI for reaction optimization).

We started this work with 3-nitroindole 6a, which was reacted with a slight excess of conjugated enolate $\mathbf{2 a}$. After 4 hours, the reaction mixture was hydrolyzed and we were pleased to observe the nearly complete conversion of the starting aromatic substrate into the expected cycloadduct 8aa, obtained as a $85: 15$ diastereomeric mixture and isolated in a global $83 \%$ yield (Scheme 2). This result thus shows the possibility of resorting to a nucleophilic activation of the diene partner in these dearomatizing formal cycloadditions. In the basic conditions of the reaction, rearomatization of the generated indoline by elimination of nitrous acid, could be anticipated but was not observed. In addition, no strong acidic treatment was required after the conjugate addition to trigger the subsequent cyclization step. This reaction compares favourably to the Diels-Alder sequences already reported between $\mathbf{6 a}$ and $1 .^{5}$ Hence, the reaction is performed at lower temperature, with a slightly higher diastereoselectivity, in conditions preventing the loss of functional groups. Noteworthy, no reaction was observed when interacting $6 \mathbf{a}$ with $3 \mathbf{a}$ in the presence of a catalytic amount of chiral secondary amine to promote the dienamine derived process (see ESI).

We then extended this methodology to other nitroindoles (see ESI for reaction optimization). 6b, Bearing a bromine substituent in position 5 , reacted in an analogous way and led to 8 ba in $61 \%$ isolated yield, and in a 77:23 d.r.. With an additional nitro substituent on the 6 -membered ring of the indole, $6 c$ reacted similarly, involving regioselectively the $\mathrm{C} 2=\mathrm{C} 3$ moiety of the 5-membered heteroaromatic part as the Michael acceptor. It furnished $\mathbf{8 c a}$ in $87 \%$ yield, as a $89: 11$ mixture of diastereomers. Dinitroindoles $\mathbf{6 d}$ and $6 \mathbf{e}$ as well as the carbamate $\mathbf{6 f}$ led to cycloadducts $\mathbf{8 d a}$, $8 \mathbf{e a}$ and $\mathbf{8 f a}$ in 86 ,
89 and $94 \%$ yield respectively in similar diastereoselectivities. The trans relative stereochemistry between the nitro and methoxy group in the major diastereomer could be confirmed by an X-Ray diffraction study on monocrystals of $\mathbf{8 f a}$ (See ESI). The substrate bearing a bromine atom in position $4,6 \mathrm{~g}$, behaved slightly differently. A larger 2.4 excess of the conjugated enolate anion was necessary to get a complete transformation. After hydrolysis, the dearomatized Michael adduct 7ga was isolated as a single trans diastereomer in $80 \%$ yield. An X-ray diffraction study confirmed this relative trans stereochemistry (See ESI). The nitronate intermediate did not spontaneously cyclize in this case and the indoline, which was expected to be unstable and give back the starting materials upon hydrolysis, proved stable and was isolated by chromatography on silica. This outcome suggests that the cyclic adducts obtained before were, as expected, formal cycloadducts, formed through a two-step sequence. The more difficult cyclization step observed in this case might be due to the steric hindrance generated by the bromine atom in position 4, close to the potentially reactive center. More surprisingly, a similar behavior was observed with the 5benzyloxyindole $6 \mathrm{~h}$, which afforded the trans Michael adduct 7ha in $77 \%$ yield. ${ }^{14}$

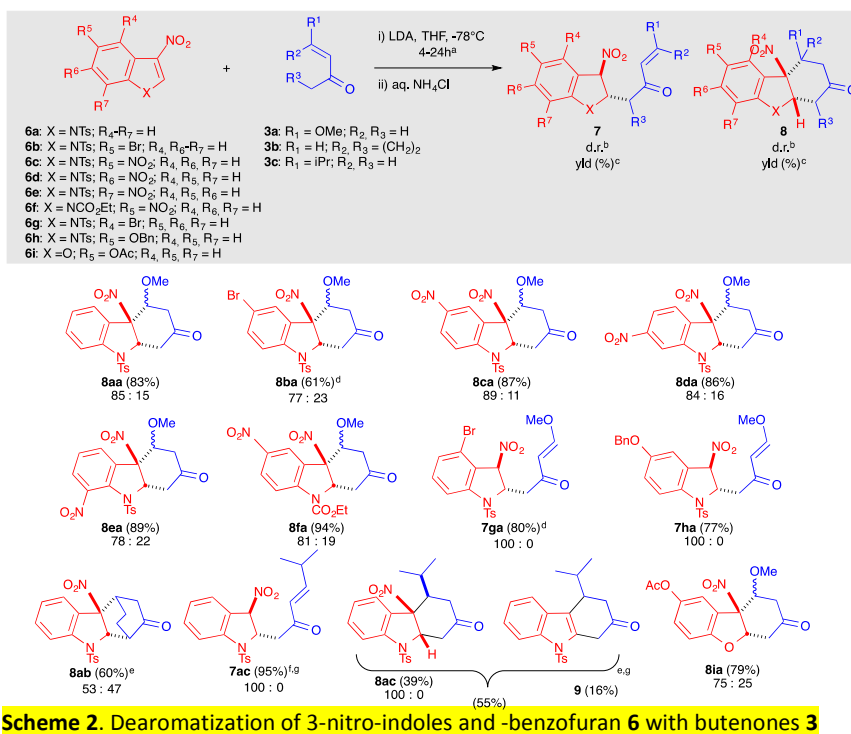

$\mathrm{a}$ : see ESI for the reaction time. $\mathrm{b}$ : determined (det.) by ${ }^{1} \mathrm{H}$ NMR on the crude mixture. $c$ : isolated overall yield. $d: 2.4$ equiv of enolate. e : The crude 1,4-adduct cyclized when treated on $\mathrm{SiO}_{2}$. f. yield of the crude 1,4-adduct, after hydrolysis. g: 1.8 equiv of enolate.

This dearomatizing methodology was next extended to differently substituted enolate anions of unsaturated ketones. The use of cyclohexenone (3b) as precursor led to the full conversion of the substrate. The resulting 1,4-adduct proved, in this case, unstable on silica and spontaneously cyclized to lead to the formal cycloadduct $8 \mathbf{a b}$, isolated in an overall $60 \%$ yield as a 53:47 mixture of diastereomers. An X-ray diffraction study of the major diastereomer allowed the assignment of the relative stereochemistries (See ESI). Noteworthy, when considering a classical NED cycloaddition process, the corresponding neutral silyloxycylohexadiene remained inert 
towards nitroindole $\mathbf{6 a}$ (thermal or organocatalyzed conditions). The isopropyl substituted enolate, generated from 5-methylhex-3-en-2-one was an even more challenging case, the hindrance imposed by the $i \operatorname{Pr}$ group being expected to slow down the cyclization step. A 59\% conversion was observed after $3 \mathrm{~h}$ at $-78^{\circ} \mathrm{C}$ when 1.2 equiv of $2 \mathrm{c}$ were used the trans Michael adduct 7ac was expectedly formed. Increasing the reaction time to $24 \mathrm{~h}$ and the excess of enolate to 1.8 equiv gratifyingly led to a $95 \%$ conversion in the 1,4 Michael adduct, which astonishingly easily cyclized to furnish the corresponding formal cycloadducts. The compound $8 \mathrm{ac}$ featuring a cis relationship between the nitro and iPr groups was isolated in a $39 \%$ yield, while rearomatized cycloadduct $\mathbf{9}$, arising from the trans cycloadduct, was obtained in a $16 \%$ yield. ${ }^{15}$ The structures of 8 ac and $\mathbf{9}$ could be firmly assigned by $\mathrm{X}$-ray analyses (see ESI).

Noteworthy, a Suzuki coupling was easily performed with the brominated tricyclic compounds $\mathbf{8 b a}$ and phenylboronic acid, under classical conditions, showing the late functionalization potential of this elaborated formal cycloadduct. ${ }^{16}$

We next considered the involvement of different nitro substituted aromatic rings to enlarge the scope of this reaction. 3-Nitrobenzofuran $6 \mathbf{i}$ reacted like nitroindoles in the presence of enolate anion $\mathbf{2 a}$, leading to the dearomatized cycloadduct 8ia directly, obtained as a 75:25 d.r. and isolated in a $79 \%$ yield.

We then envisaged these dearomatization reactions with more demanding nitroarenes, such as naphthalenic compounds, renowned for their high stability. When reacted with an excess of enolate $\mathbf{2} \mathbf{a}$ under the reaction conditions used above, 1,5dinitronaphthalene proved inert. Increasing the reaction time or the excess of enolate did not improve the result (Table 1 , entry 1). Performing it at higher reaction temperatures did not facilitate the transformation either while secondary adducts resulting from the self-condensation of the conjugated enolate on its precursor were observed.

Lithium enolate species are known to form aggregates and their reactivities to be notably influenced by the size of these clusters. Addition of deaggregating agents is known to favour smaller and more reactive nucleophilic species, a phenomenon reported to play a positive role on the reactivity of lithium species. ${ }^{17}$ Addition of 1.2 equiv of TMEDA to the reaction mixture proved encouraging, allowing the formation of traces of the expected 1,4-adduct 10a (entry 2). Even if insufficient, this result suggests that its aggregation state indeed tunes the reactivity of the conjugated enolate anion in these transformations. Switching from TMEDA to DMPU improved the conversion to $28 \%$ (entry 3 ) and the best result was obtained with HMPA which allowed to get nearly complete conversion of the dinitronaphtalene into its dearomatized Michael adduct 10a (entry 4). The 1,4-adduct 10a was stable enough to be purified by column chromatography and could be isolated in a $79 \%$ yield as a single trans diastereomer. ${ }^{18}$ Increasing the amount of HMPA led to a full conversion and a slightly increased $82 \%$ isolated yield (entry 5). Noteworthy, heating the crude mixture under vacuum to remove the excess
HMPA, led to re-aromatization into naphtalene 11, after elimination of nitrous acid (Scheme 3 ).

Table 1. Dearomatization of dinitronaphthalene and nitropyridine

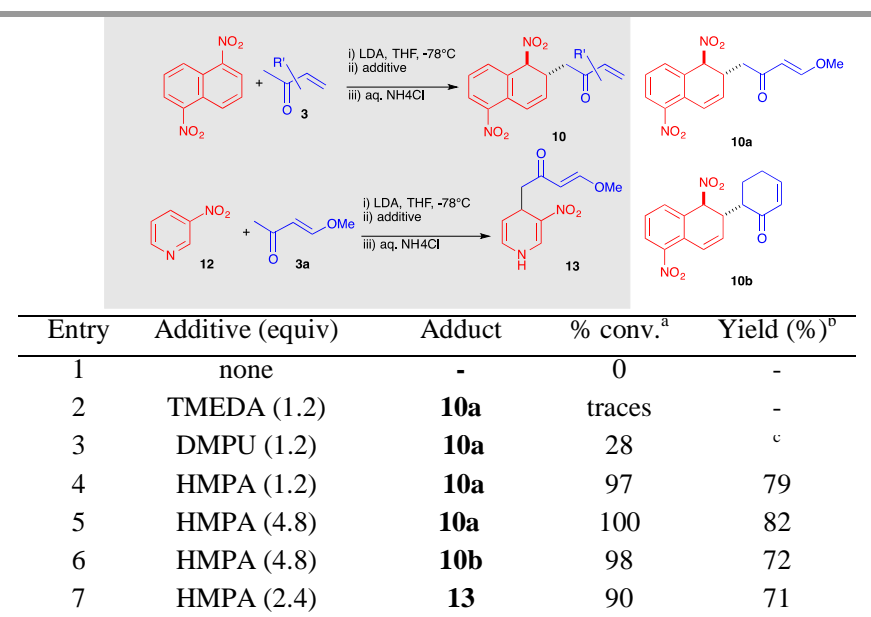

a : det. by ${ }^{1} \mathrm{H}$ NMR on the crude mixture. $b$ : isolated yield. $c$ : not det.

The methodology was next extended to another conjugated enolate partner, using cyclohexenone as precursor. Here again, in the presence of HMPA, the dearomatizing nucleophilic addition occurred at $-78^{\circ} \mathrm{C}$, furnishing the expected 1,4adduct $\mathbf{1 0 b}$ as a single diastereomer in a $72 \%$ yield (Table 1 , entry 6).

We then envisioned this methodology with the electrondepleted 3-nitropyridine (12). Here again, in the absence of HMPA, no reaction took place, while, with HMPA, enolate $2 \mathrm{a}$ added onto the pyridine core, leading to the 1,4dihydropyridine 13 (71\% isolated yield, entry 7). The regiochemistry of this adduct is in line with reported results on nucleophilic additions involving pyridines bearing an electrondeficient substituent in position $3 .^{2 a, 19}$

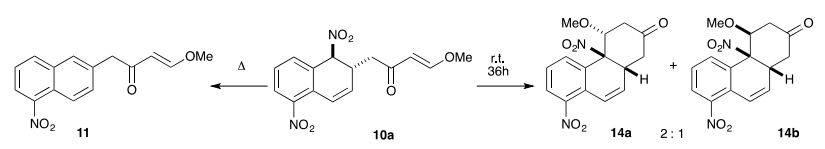

Scheme 3. Transformation of 1,4-adduct 10a

Interaction of conjugated enolate $\mathbf{2 a}$ with 1,5dinitronaphthalene furnished the 1,4-adduct 10a, and no traces of cyclized compound were detected in the crude mixture. However, when the crude was maintained at room temperature for $36 \mathrm{~h}$, it fully cyclized into the formal cycloadducts $14 \mathrm{a}$ and $14 \mathrm{~b}$ (2:1 ratio). These two diastereomers were separated by column chromatography and isolated in a $53 \%$ overall yield (for the two steps sequence). The relative stereochemistries of $\mathbf{1 4 a}$ and $\mathbf{1 4 b}$ were assigned by NOESY experiments (See ESI). This methodology thus furnishes the dearomatized $(4+2)$ cycloadducts in smooth conditions. In constrast to classical NED cycloaddition on nitronaphtalenes, rearomatization is not observed. The functional groups are preserved in the products, paving the way to diverse derivatization reactions. 


\section{Conclusions}

In conclusion, the results described herein show that "conventional» nitroaromatic derivatives can be dearomatized at low temperature in classical conditions using highly nucleophilic lithium enolates derived from simple methyl vinyl ketone derivatives. Trans 1,4-adducts are isolated or go one-step beyond and cyclize to furnish the corresponding formal cycloadducts. This method thus represents an unusual dearomatizing (4+2) formal cycloaddition process promoted by a nucleophilic activation mode, in conditions compatible with many substrates and functionalities. While nitroindoles react with the conjugated enolate anion generated in situ from the corresponding butenones, deaggregation of the nucleophilic species with HMPA enhances its nucleophilic character and extends the scope of the dearomatizing process to more challenging aromatic substrates, such as naphthalenes or pyridines. Nitroaromatics thus behave as Michael acceptors and lead to the formation of 3D (poly)cyclic derivatives advantageously functionalized, that constitute scaffolds prone to potentially interesting derivatizations. Efforts to extend this reactivity to other aromatics and enolates systems are currently under way.

\section{Conflicts of interest}

There are no conflicts to declare.

\section{Acknowledgment}

Financial support from the ANR (ANR-17-CE07-0050), Labex SynOrg (ANR-11-LABX-0029). CRIANN (Saint Etienne du Rouvray, France) for their allocation of computer time. Author Contributions: K.P. and B.R. contributed equally to this work.

\section{Notes and references}

1 See for instance: a) F. Lovering, J. Bikker and C. Humblet, J. Med. Chem., 2009, 52, 6752. b) J. Meyers, M. Carter, N. Y. Mok and N. Brown, Future Med. Chem., 2016, 8, 1753.

2 For reviews on dearomatization strategies, see for instance : a) F. López Ortiz, M. J. Iglesias, I. Fernández, C. M. Andújar Sánchez and G. Ruiz Gómez, Chem. Rev., 2007, 107, 1580. b) S. P. Roche and J. A. Porco, Angew. Chem. Int. Ed., 2011, 50, 4068. c) J. A. Bull, J. J. Mousseau, G. Pelletier and A. B. Charette, Chem. Rev., 2012, 112, 2642. d) S. P. Roche, J.-J. Youte Tendoung and B. Tréguier, Tetrahedron, 2015, 71, 3549. e) W.-T. Wu, L. Zhang and S.-L. You, Chem. Soc. Rev., 2016, 45, 1570. f) W. C. Wertjes, E. H. Southgate and D. Sarlah, Chem. Soc. Rev., 2018, 47, 7996. g) G. Bertuzzi, L. Bernardi and M. Fochi, Catalysts, 2018, 8, 632.

3 For reviews, see for instance : a) C. Oliver Kappe, S. Shaun Murphree and A. Padwa, Tetrahedron, 1997, 53, 14179. b) J. C. C. Atherton and S. Jones, Tetrahedron, 2003, 59, 9039. c) B. K. Liebov and W. D. Harman, Chem. Rev., 2017, 117, 13721.

4 For non-nitrated arenes involved as electron-poor dienophiles, see for instance: a) E. Wenkert, P. D. R. Moeller and S. R. Piettre, J. Am. Chem. Soc., 1988, 110, 7188. b) G. A. Kraus, D. Bougie, R. A. Jacobson and Y. Su, J. Org. Chem., 1989, 54, 2425. c) B. Biolatto, M. Kneeteman, E. Paredes and
P. M. E. Mancini, J. Org. Chem., 2001, 66, 3906. d) A. Chrétien, I. Chataigner, N. L'Hélias and S. R. Piettre, J. Org. Chem., 2003, 68, 7990. e) A. Chrétien, I. Chataigner and S. R. Piettre, Chem Commun, 2005, 1351. f) J. Boonsombat, H. Zhang, M. J. Chughtai, J. Hartung and A. Padwa, J. Org. Chem., 2008, 73, 3539. g) S. France, J. Boonsombat, C. A. Leverett and A. Padwa, J. Org. Chem., 2008, 73, 8120. h) N. Chopin, H. Gérard, I. Chataigner and S. R. Piettre, J. Org. Chem., 2009, 74, 1237. i) A. S. Kil'met'ev, E. E. Shul'ts, M. M. Shakirov, T. V. Rybalova and G. A. Tolstikov, Russ. J. Org. Chem., 2013, 49, 872.

5 For nitro-indoles, -pyrroles or -naphthalenes involved as dienophiles in Diels-Alder cycloadditions, see for instance: a) T. L. S. Kishbaugh and G. W. Gribble, Tetrahedron Lett., 2001, 42, 4783. b) E. Paredes, B. Biolatto, M. Kneeteman and P. Mancini, Tetrahedron Lett., 2002, 43, 4601. c) E. Paredes, R. Brasca, M. Kneeteman and P. M. E. Mancini, Tetrahedron, 2007, 63, 3790. d) M. Andreini, M. De Paolis and I. Chataigner, Catal. Commun., 2015, 63, 15. e) Y. Li, F. Tur, R. P. Nielsen, H. Jiang, F. Jensen and K. A. Jørgensen, Angew. Chem. Int. Ed., 2016, 55, 1020. For (4+2) annulations on indoles, see: f) D.-F. Yue, J.-Q. Zhao, X.-Z. Chen, Y. Zhou, X.M. Zhang, X.-Y. Xu and W.-C. Yuan, Org. Lett., 2017, 19, 4508. g) D. Cao, A. Ying, H. Mo, D. Chen, G. Chen, Z. Wang and J. Yang, J. Org. Chem., 2018, 83, 12568.

6 See: E. J. Corey, Angew. Chem. Int. Ed., 2002, 41, 1650.

7 See for instance: T. Mukaiyama and T. Kitazawa, Heterocycles, 2006, 69, 417.

8 For a review, see for instance: K. Matsumoto, H. Hamana and H. lida, Helv. Chim. Acta, 2005, 88, 2033.

9 See for instance: a) E. Arceo and P. Melchiorre, Angew. Chem. Int. Ed., 2012, 51, 5290. b) I. Kumar, P. Ramaraju and N. A. Mir, Org Biomol Chem, 2013, 11, 709.

10 R. Baker, D. L. Selwood, C. J. Swain, N. M. H. Webster and J. Hirshfield, J. Chem. Soc. [Perkin 1], 1988, 471.

11 Y. Zhang and S. J. Danishefsky, J. Am. Chem. Soc., 2010, 132, 9567.

12 J. M. Eagan, M. Hori, J. Wu, K. S. Kanyiva and S. A. Snyder, Angew. Chem. Int. Ed., 2015, 54, 7842.

13 Isolation of the same cyclobutenone after TFA treatment, in a similar yield, was observed.

14 This is reminiscent of results reported in related $(3+2)$ dearomatizing annulations, see: $M$. Laugeois, J. Ling, C. Férard, V. Michelet, V. Ratovelomanana-Vidal and M. R. Vitale, Org. Lett., 2017, 19, 2266.

15 Trying to increase the yield of the cyclization step led to either the formation of the re-aromatized cycloadduct 9 or recovery of the starting indole, by retro-Michael reaction.

16 See for instance: M. A. Düfert, K. L. Billingsley and S. L. Buchwald, J. Am. Chem. Soc., 2013,

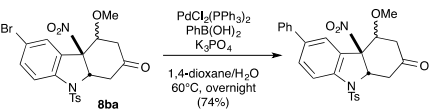
135,12877

17 See for instance: a) Z. A. Fataftah, I. E. Kopka and M. W Rathke, J. Am. Chem. Soc., 1980, 102, 3959. b) T. Mukhopadhyay and D. Seebach, Helv. Chim. Acta, 1982, 65, 385. c) M. Goto, K. Akimoto, K. Aoki, M. Shindo and K. Koga, Tetrahedron Lett., 1999, 40, 8129. d) X. Sun and D. B. Collum, J. Am. Chem. Soc., 2000, 122, 2459. e) M. Suzuki, H. Koyama and R. Noyori, Bull. Chem. Soc. Jpn., 2004, 77, 259. f) K. J. Kolonko, M. M. Biddle, I. A. Guzei and H. J. Reich, J. Am. Chem. Soc., 2009, 131, 11525. g) J. Guang, Q. P. Liu, R. Hopson and P. G. Williard, J. Am. Chem. Soc., 2015, 137, 7347. h) M. J. Houghton and D. B. Collum, J. Org. Chem., 2016, 81, 11057.

18 The trans stereochemistry of $10 \mathrm{a}$ was assigned by ${ }^{1} \mathrm{H}$ NMR scalar couplings and comparison with DFT estimated values. (see ESI). 
Journal Name

19 G. Bertuzzi, A. Sinisi, D. Pecorari, L. Caruana, A. Mazzanti, L. Bernardi and M. Fochi, Org. Lett., 2017, 19, 834 and references therein. 